\title{
PAP SMEAR FOR SCREENING OF CARCINOMA CERVIX
}

\author{
Minakeshi Rana1, Surinder Kumar Atri², Shweta Bhagat ${ }^{3}$, Varinder Mohan Rana ${ }^{4}$
}

${ }^{1}$ Consultant, Department of Obstetrics and Gynaecology, DH Samba, Jammu, J \& K Health Services, Jammu and Kashmir, India. ${ }^{2}$ Associate Professor, Department of Pathology, Government Medical College, Jammu, Jammu and Kashmir, India. 3Junior Resident, Department of Obstetrics and Gynaecology, Government Medical College, Jammu, Jammu and Kashmir, India. ${ }^{4}$ Medical Officer, DH Rajouri, J \& K Health Services, Jammu and Kashmir, India.

ABSTRACT

\section{BACKGROUND}

A cross sectional study to measure the prevalence of carcinoma cervix and to correlate these abnormalities with clinical features in women attending gynaecology clinic at District Hospital Samba, Jammu (Hospital based study). All women (114) who attended gynaecology clinic with signs and symptoms of diseases of cervix were included in the study.

\section{MATERIALS AND METHODS}

Pap smears were made with wooden spatula and immediately fixed in fixative and evaluated by conventional cytology. Pap smear diagnosis was correlated with presenting symptoms of patients.

\section{RESULTS}

Age of patients ranged from 18-77 years and mean age was 31.41 years. Most of the patients were para 1 or para 2 . Discharge per vaginum was the most common symptom (39.13\%) followed by pain lower abdomen (37.68\%), menstrual abnormalities (15.94\%) and bleeding per vaginum (7.25\%). Pap smear diagnoses were: Normal Cervical Smears: 9 (8.33\%), Inflammatory Cervical Smear: 85 (75\%), Infection 6 (5.27 \%), Atrophic Smear: 1 (0.44 \%), LSIL: 7 (6.14 \%), Inadequate for Evaluation: 6 (4.82 \%).

\section{CONCLUSION}

This study establishes the importance of cervical cancer screening by conventional Pap smears in diagnosing precancerous lesions of cervix and can be supplemented by HPV testing.

\section{KEY WORDS}

Carcinoma Cervix, Pap Smear, LSIL/HSIL and HPV.

HOW TO CITE THIS ARTICLE: Rana M, Atri SK, Bhagat S, et al. Pap smear for screening of carcinoma cervix. J. Evolution Med. Dent. Sci. 2019;8(07):437-440, DOI: 10.14260/jemds/2019/96

\section{BACKGROUND}

Cervical cancer is common worldwide and ranks third among all malignancies for women. Eighty percent of cancer cervix cases are seen in developing countries, where it is commonest cancer in women. ${ }^{1}$ In 2008 , an estimated 5,30 , 000 new cases were identified globally and 2, 75, 000 deaths were recorded. India had an age standardized incidence rate of $30.7 / 100,000$ women in 2002, one -year prevalence of 101,583 and 5-year prevalence of 370, 243 and 72, 600 deaths in $2002.2,3$

Human papilloma virus infection is a well-known prerequisite for the development of cervical cancer. The risk factors for cervical cancer are related to both host and viral characteristics such as HPV exposure, viral oncogenicity, inefficiency of immune response and presence of cocarcinogens. ${ }^{4}$ The predisposing factors for carcinoma cervix include- early age at marriage, coitus before 18 year of age, delivery of the first baby before the age of 20 year, multiple sex partners, history of genital warts, high parity, use of oral

'Financial or Other Competing Interest': None.

Submission 10-01-2018, Peer Review 04-02-2019,

Acceptance 07-02-2019, Published 18-02-2019.

Corresponding Author:

Dr. Surinder Kumar Atri,

Associate Professor,

House No. 24, Lane 51, Behind Sunny Farms,

Greater Kailash Post Office, Gangyal, Jammu,

Jammu and Kashmir, India.

E-mail: surinderkumaratri@gmail.com

DOI: $10.14260 /$ jemds/2019/96 contraceptives, race and religion; cancer cervix is rare in Muslims and Jews; circumcision may be a factor. Low socioeconomic status and poor personal hygiene may be contributory factors. 5 Persistent infection with high risk oncogenic HPVs (HPV 16 and HPV 18) is currently considered to be the single most important factor in cervical oncogenesis. ${ }^{6}$ Moreover, the integration of high-risk HPV is a key step in cervical neoplastic progression. ${ }^{7}$ Tobacco specific carcinogens and polycyclic aromatase hydrocarbons can bind to and damage cellular DNA and may cooperate with HPV to produce malignant transformation. Prenatal exposure to the diethylstilboestrol and development of the clear cell adenocarcinoma of the cervix is also observed. ${ }^{8}$ Association of herpes simplex virus 2 and Chlamydia trachomatis with cancer cervix is being investigated. ${ }^{9}$ Epidemiological studies showed that diet deficient in fruits and vegetables and a low intake of $\beta$-carotene are associated with increased risk of cervical dysplasia. ${ }^{10}$

Nearly all the invasive cervical carcinomas are preceded by a stage in which abnormal cells are confined to the epithelium. These intraepithelial lesions share many of the cytologic features of the invasive carcinoma, mainly manifested by enlargement, irregularities and hyperchromasia of the nuclei; increase in mitotic activity and alteration of maturation pattern. A continuous range of the morphological abnormalities exist among these lesions, which provide a rough indication of the likelihood with which they will evolve into invasive carcinoma if left untreated.11,12 According to the Bethesda System, these are pre-invasive lesions are classified into two groups: Low grade squamous 
intraepithelial lesions (LSIL) and high grade squamous intraepithelial lesions (HSIL). The available evidence suggests the existence of a sequence of events that in some cases leads to the progression to a full-blown invasive malignancy while some milder forms regress spontaneously. Cancer of the cervix can be prevented by interpreting it at the preinvasive stage. $13,14,15$

Cervical cancer is considered preventable, as majority of cancers are preceded by a long-standing precancerous lesion. This lesion may exist in the non-invasive stage for years and shed abnormal cells that can be detected on cytological examination. ${ }^{16}$

The Papanicolaou (Pap) smear is one of the modern success stories in the field of preventive medicine which detects cervical cancer in its early stages. The Pap test is a screening test performed using cells from ectocervix, endocervix and vagina.

The conventional Pap smear test is used widely in developed countries, where it has decreased both the incidence and mortality of carcinoma cervix. It has been estimated that the use of this simple and cost-effective technique has reduced the incidence of carcinoma cervix by at least by $70 \%$, yet false positive results are common. Unfortunately, many developing countries lack the facility to carry out widespread Pap screening.17,18,19 Therefore we planned this study to measure the prevalence carcinoma cervix among women attending Gynaecology OPD (Hospital based)

\section{MATERIALS AND METHODS}

A cross sectional study was conducted on 114 women attending gynaecology OPD with sign and symptoms suspicious of disease of cervix at District hospital Samba, Jammu; Jammu and Kashmir from March 2013 to February 2014. The women who presented with symptoms like vaginal discharge, perineal itching, lower abdominal pain, backache, menstrual abnormalities and postcoital bleeding were included in the study. In each case detailed history, gynaecological/ obstetrics history, general physical examination and per vaginum examination was done. Pap smears were prepared in lithotomy position, the gynaecologist inserted a speculum into vagina and then using a wooden spatula took a sample of cells from and around the cervix; ensuring adequate sampling of squamocolumnar junction, this material was then smeared on glass slides and immediately fixed in $90 \%$ methanol or $90 \%$ propanol and then sent to cytology laboratory for evaluation.

\section{RESULTS}

Age of patients ranged from 18 - 77 year and mean age was 31.41 year. Most of the patients were para 1 or para 2 however para 4 or para 5 patients were also there. Discharge per vaginum was the most common symptom (39.13\%) followed by pain lower abdomen $(37.68 \%)$ and menstrual abnormalities (15.94\%). Bleeding per vaginum was in only five cases $(7.25 \%)$.

Out of a total of 114 Pap smears that were evaluated for cytomorphological features, 9 cases were diagnosed as normal cervical smears, 85 (75\%) cases were diagnosed as inflammatory cervical smears, $6(5.27 \%)$ cases were diagnosed as infection in smears, $1(0.44 \%)$ case was of atrophic smear, 7 (6.14\%) cases were diagnosed as LSIL and
$6(4.82 \%)$ cases were inadequate for evaluation. Various diagnoses rendered on Pap smears are illustrated in table 1.

\begin{tabular}{|c|c|c|}
\hline Pap Smear Diagnosis & No. & $\%$ \\
\hline Normal Cervical Smear & 9 & 8.33 \\
\hline Inflammatory Cervical Smear & 85 & 75.0 \\
\hline Organisms Bacterial Vaginoses & 5 & 4.39 \\
\hline Trichomonas Vaginalis & 1 & 0.88 \\
\hline Atrophic Smear & 1 & 0.44 \\
\hline LSIL & 7 & 6.14 \\
\hline Inadequate for Evaluation & 6 & 4.82 \\
\hline Total & 114 & 100.0 \\
\hline \multicolumn{3}{|c|}{ Table 1. Pap Smear Diagnosis } \\
\hline
\end{tabular}

Pap smear diagnoses in patients who presented with discharge per vaginum is shown in table 2

\begin{tabular}{|c|c|c|c|c|c|}
\hline $\begin{array}{c}\text { Clinical } \\
\text { Feature }\end{array}$ & Normal & Inflammatory & Organisms & Atrophic & LSIL \\
\hline $\begin{array}{c}\text { Discharge } \\
\text { per Vaginum }\end{array}$ & 3 & 18 & 2 & 0 & 4 \\
\hline
\end{tabular}

Table 2. Pap Smear Diagnosis in Patients Who Presented with Discharge Per Vaginum

Pap smear diagnoses in patients who presented with pain lower abdomen is shown in table 3 .

\begin{tabular}{|c|c|c|c|c|c|}
\hline $\begin{array}{c}\text { Clinical } \\
\text { Feature }\end{array}$ & Normal & Inflammatory & Organisms & Atrophic & LSIL \\
\hline $\begin{array}{c}\text { Pain Lower } \\
\text { Abdomen }\end{array}$ & 2 & 20 & 2 & 0 & 3 \\
\hline Table 3. Pap Smear Diagnosis in Patients Who Presented \\
with Pain Lower Abdomen \\
\hline
\end{tabular}

Pap smear diagnoses in patients who presented with menstrual abnormalities is shown in table 4 .

\begin{tabular}{|c|c|c|c|c|c|}
\hline $\begin{array}{c}\text { Clinical } \\
\text { Feature }\end{array}$ & Normal & Inflammatory & Organisms Atrophic & LSIL \\
\hline $\begin{array}{c}\text { Menstrual } \\
\text { Abnormalities }\end{array}$ & 1 & 7 & 1 & 0 & 2 \\
\hline
\end{tabular}

Table 4. Pap Smear Diagnosis in Patients Who Presented with Menstrual Abnormalities

Pap smear diagnoses in patients who presented with bleeding per vaginum is shown in table 5 .

\begin{tabular}{|c|c|c|c|c|c|}
\hline $\begin{array}{c}\text { Clinical } \\
\text { Feature }\end{array}$ & Normal & Inflammatory & Organisms & Atrophic & LSIL \\
\hline $\begin{array}{c}\text { Bleeding } \\
\text { per } \\
\text { Vaginum }\end{array}$ & 0 & 3 & 1 & 0 & 1 \\
\hline \multicolumn{5}{|c|}{ Table 5. Pap Smear Diagnosis in Patients Who Presented } \\
with Bleeding Per Vaginum \\
\hline
\end{tabular}

\section{DISCUSSION}

The clinico-cytological evaluation of 114 cervical smears establishes the spectrum of hospital-based lesions of cervix in India. It also establishes the importance of cervical cancer screening by cervical Pap smears. The cervical Pap smear screening is useful for developing countries like India where majority of population is rural and belong to low socioeconomic status and cannot afford universal screening and newer techniques like liquid-based cytology, automated scanning devices, computer assisted microscopy, digital 
colposcopy with automated image analysis, human papilloma virus testing, molecular markers and HPV vaccine. Using conventional cytology, a definite diagnosis could be reached in 108 of total 114 cases. The cytology diagnoses of cancer cervix and precursor lesions (LSIL/HSIL) has to be confirmed by histopathology which is considered gold standard. Based on cytohistology correlation, conventional cervical Pap smear test is not sufficiently sensitive in reliably detecting cervical intraepithelial neoplasia. ${ }^{20} \mathrm{~A}$ median analysis of European studies has shown that the median sensitivity of conventional cytology is only $50 \%$, but with marked variation in sensitivity in different national settings. ${ }^{21}$ It is because of this low sensitivity and specificity of cervical Pap smears, newer techniques for cervical cancer screening were introduced.

Inflammatory cervical smear was the commonest diagnoses rendered in evaluation of cervical smears i.e., 85 cases out of 114 cases. This was followed by normal cervical smear, LSIL, unsatisfactory smears, microbial infection and atrophic smears. Most of the patients in our study were symptomatic who attended gynaecology clinic for some complaints, and this could be the reason for inflammatory cervical smears being the commonest diagnosis encountered. Had it been the screening of general population/random screening the incidence of different diagnoses rendered would have been different. The results of other studies also support this observation.22,23 Persistent inflammatory cervical smears can lead to chronic irritation and can be fertile soil for neoplastic transformation. ${ }^{24}$ In our study the incidence of normal cervical smears is low as most of the patients were attending gynaecology clinic for some complaints and none of the patient was volunteer for cervical cancer screening. ${ }^{23,24}$ In our study, the diagnoses of LSIL was in seven cases $(6.14 \%)$ out of total of 114 cases. This establishes the importance cervical Pap smears in diagnosing precancerous lesions of cervix. LSIL cases are followed up clinically and repeat Pap smear is done after one year. The study by Mufti ST et al (2014) ${ }^{25}$ diagnosed LSIL in $2.2 \%$ cases. There was a single case of atrophic smear in our study and she was 77-year-old. The incidence of atrophic smears was much less compared to the studies in the literature.26,27 This could be because of less number of postmenopausal women in our study. We found six cases of infectious smears which included five cases of bacterial vaginoses and one case of Trichomonas vaginalis. The reporting of bacterial vaginoses is important as it predisposes to postoperative infections, preterm delivery, chorioamnionitis, urinary tract infections, endometritis and pelvic inflammatory disease. The reporting of Trichomonas is also important since they are also associated with adverse pregnancy outcomes, such as premature rupture of membranes, preterm-delivery, low birth weight as well as increased risk of HIV transmission.

\section{CONCLUSION}

In our country where majority of population is rural, screening for carcinoma cervix by Pap smears and conventional cytology can play an important role in diagnosing precancerous lesions of cervix and thus can play an important role in decreasing the incidence of carcinoma cervix. This study also establishes that conventional cytology Pap smear screening has low sensitivity and needs to be supplemented by HPV testing, and liquid based cytology.

\section{REFERENCES}

[1] Tamboli GD, Khatod LV. Accuracy of cytological findings in abnormal cervical smear by cytohistological comparison. Journal of Medical Education \& Research 2013;3(2):19-24.

[2] Arbyn M, Castellsague $X$, De Sanjose $S$, et al. Worldwide burden of cervical cancer in 2008. Ann Oncol 2011;22(12):2675-86.

[3] GLOBOCAN. International Agency for Research on Cancer: 2002 database. http://globocan.iarc.fr/factsheet.asp.

[4] Shiffman M, Castle PE, Jeronimo J, et al. Human papillomavirus and cervical cancer. Lancet 2007;370(9590):890-907.

[5] Bayo S, Bosch FX, De Sanjose S, et al. Risk factors of invasive cervical cancer in Mali. Int J Epidemiol 2002;31(1):202-9.

[6] Munoz N, Bosch FX, De Sanjose S, et al. Epidemiologic classification of human papilloma virus types associated with cervical cancer. $\mathrm{N}$ Engl J Med 2003;348(6):518-27.

[7] Hellberg D, Nilsson S, Haley NJ, et al. Smoking and cervical intraepithelial neoplasia: nicotine and cotinine in serum and cervical mucus in smokers and nonsmokers. Am J Obstet Gynecol 1988;158(4):910-3.

[8] Herbst AL, Cole P, Norusis MJ, et al. Epidemiologic aspects and factors related to survival in 384 registry cases of clear cell adenocarcinoma of the vagina and cervix. Am J Obstet Gynecol 1979;135(7):876-86.

[9] Kwasniewska A, Korobowicz E, Zdunek M, et al. Prevalence of Chlamydia trachomatis and herpes simplex virus 2 in cervical carcinoma associated with human papillomavirus detected in paraffin-sectioned samples. Eur J Gynaecol Oncol 2009;30(1):65-70.

[10] Keefe KA, Schell MJ, Brewer C, et al. A randomized, double blind, Phase III trial using oral beta-carotene supplementation for women with high-grade cervical intraepithelial neoplasia. Cancer Epidemiol Biomarkers Prev 2001;10(10):1029-35.

[11] Johnson LD, Nickerson RJ, Easterday CL, et al. Epidemiologic evidence for the spectrum of change from dysplasia through carcinoma in situ to invasive cancer. Cancer 1968;22(5):901-14.

[12] Ostor AG. Natural history of cervical intraepithelial neoplasia: a critical review. Int J Gynecol Pathol 1993;12(2):186-92.

[13] Kolstad P, Klem V. Long-term follow-up of 1121 cases of carcinoma in situ. Obstet Gynecol 1976;48(2):1259.

[14] Fox CH. Biological behavior of dysplasia and carcinoma in situ. Am J Obstet Gynecol 1967;99(7):960-74.

[15] Richart RM, Barron BA. A follow-up study of patients with cervical dysplasia. Am J Obstet Gynecol 1969;105(3):386-93.

[16] Banik U, Bhattacharjee P, Ahamad SU, et al. Pattern of epithelial cell abnormality in Pap smear: a clinicopathological and demographic correlation. Cytojournal 2011;8:8.

[17] Zamani N. Management of Abnormal Cervical Cytology. J Coll Physc Surg Pak 1994;4:28-9. 
[18] Yousaf A, Yoasaf NW. Review of Cervical Intraepithelial Neoplasia (CIN) latest concepts of screening and management protocol. Pak J Obstet Gynaecol 1992;5:23-5.

[19] Singh P, Ilancheran A. The 'Pap' or cervical smear and the role of colposcopy in screening for carcinoma of the cervix. Singapore Med J 1989;30(3):302-5.

[20] McGoogan E, Reith A. Would monolayers provide more representative samples and improved preparations for cervical screening? Overview and evaluation of systems available. Acta Cytol 1996;40(1):107-19.

[21] Isaoglu U, Yilmaz M, Delibas IB, et al. Evaluation of 37, 438 consecutive cervical smear results in the Turkish population. Arch Med Sci 2015;11(2):402-5.

[22] Bhojani KR, Garg R. Cytopathological study of cervical smears and co-relation of findings with risk factors. Int J Biol Med Res 2011;2(3):757-61.

[23] Hirachand S, Bajracharya J, Pradhanang S, et al. Detection of abnormal cervical cytology in papanicolaou smears in a tertiary care center. J Nepal Med Assoc 2013;52(191):462-5.
[24] Achour M, Zeghal D. Cervical cancer in women with inflammatory pap smears. Journal of Cancer Therapy 2014;5:82-90.

[25] Mufti ST, Altaf FJ. Changing pattern of epithelial cell abnormalities using revised Bethesda system. Iran J Basic Med Sci 2014;17(10):779-84.

[26] Rathod GB, Singla D. Histopathological vs. cytological findings in cervical lesions (Bethesda system) - a comparative study. International Archives of Integrated Medicine 2015;2(8):13-6.

[27] Tapasvi I, Tapasvi C, Aggarwal A. To co-relate the effect of parity, age of marriage, religion, socioeconomic status and contraception practiced in the development of premalignant and malignant lesions of cervix. International Journal of Research in Health Sciences 2015;3(1):174-8. 